\title{
A ESCOLA E SEU ENTORNO: O COTIDIANO DE ESTUDANTES REPRESENTADO A PARTIR DE RELAÇÕES E PRÁTICAS ESPACIAIS
}

\author{
Lígia Cardoso Carlos \\ Universidade Federal de Pelotas (UFPel), Faculdade de Educação, Pelotas, RS, Brasil \\ li.gi.c@hotmail.com.br \\ Rosângela Lurdes Spironello \\ Universidade Federal de Pelotas (UFPel), Instituto de Ciências Humanas, Pelotas, RS, Brasil \\ spironello@gmail.com
}

\begin{abstract}
RESUMO
O estudo apresenta resultados de uma pesquisa realizada em escola pública com estudantes de nono ano, do Ensino Fundamental. Buscou-se conhecer suas práticas espaciais cotidianas por meio da elaboração de mapas mentais, tendo como base de análise a metodologia de Kozel (2007) e Lynch (1997). As categorias geográficas lugar e território possibilitaram compreender aspectos do cotidiano da comunidade escolar e indicar potencialidades da educação geográfica no que se refere ao ensino e à gestão escolar. Como resultados, os sujeitos da pesquisa manifestaram a partir das discussões e representações, ausências, tais como: calçamento, áreas de lazer e serviços de saúde, e evidenciaram também desejos e problemas associados à juventude global, como o convívio com situações de uso e comércio de drogas e a precariedade de acesso à internet. Destacaram ainda que querem permanecer na comunidade, o que indica, por um lado, uma espécie de conformismo, ou até de naturalização da precariedade, mas que, de outro, demonstra traços de uma identidade com o lugar.
\end{abstract}

Palavras-chave: Educação geográfica. Práticas espaciais cotidianas. Comunidade escolar. Mapas mentais.

THE SCHOOL AND ITS SURROUNDINGS:

\section{THE STUDENT DAILY LIFE REPRESENTED FROM SPACE RELATIONS AND PRACTICES}

\begin{abstract}
The study presents the result of a research performed in a public school with students from the ninth grade of elementary school. The research fetched to know everyday spatial practices through the elaboration of mental maps, based on the analysis of the methodology of Kozel (2007) and Lynch (1997). The spatial categories place and territory made it possible to understand aspects of the daily life of the community and to indicate the potential of geographic education for teaching and school management. As a result, the research subjects expressed absences from the discussions and representations, such as: sidewalks, recreation areas and health services, as well as desires and problems associated with global youth, such as conviviality with situations of use and trade of drugs and the precarious access to the internet. They also emphasized that they want to remain in the community, which indicates, on the one hand, a kind of conformism, or even a naturalization of precariousness, but which, on the other hand, shows traces of an identity with the place.
\end{abstract}

Keywords: Geographic education. Everyday spatial practices. School Community. Mental maps.

\section{INTRODUÇÃO}

O presente artigo trata de uma pesquisa realizada em escola pública periférica que buscou, por meio de mapas mentais produzidos por estudantes do ensino fundamental, apreender práticas espaciais presentes em seus cotidianos, indicando potencialidades da educação geográfica para o ensino e para a gestão escolar. Nessa perspectiva, tomamos categorias espaciais de análise para investigar e compreender aspectos da comunidade da qual fazem parte, bem como, possibilitar proposições com intencionalidade pedagógica envolvendo a escola e seu entorno.

$\begin{array}{lllll}\text { Caminhos de Geografia } & \text { Uberlândia-MG } & \text { v. 22, n. } 83 & \text { out./2021 } & \text { p. 276-286 Página } 276\end{array}$


Nesse âmbito, a pesquisa produziu subsídios para a compreensão do contexto socioespacial do grupo de estudantes investigados, o qual inclui as relações com a comunidade da qual fazem parte. Partimos do pressuposto de que há, de modo geral, pouco conhecimento sobre as vivências, experiências e expectativas dos estudantes em seus cotidianos, inibindo o diálogo entre os sujeitos da/na escola e, consequentemente, dificultando a formação em uma perspectiva de educação para o exercício da cidadania.

Organizamos a escrita em dois momentos de abordagem. Incialmente, buscamos explicitar como a educação geográfica é compreendida no âmbito de nosso grupo de pesquisa, sustentada e em diálogo com autores de referência para este campo de estudos, privilegiando contextos escolares e de formação de professores. No segundo momento, apresentamos aspectos da pesquisa que evidenciam a articulação entre relações espaciais, práticas espaciais e os sujeitos envolvidos na pesquisa, por meio de mapas mentais.

\section{CIDADANIA, EDUCAÇÃO GEOGRÁFICA E O CONTEXTO ESCOLAR}

Tratamos a educação geográfica como um conhecimento que dá suporte para a compreensão do espaço no qual os sujeitos estão inseridos, construído por meio de ações com intencionalidade pedagógica, tanto escolares quanto não escolares. Essa compreensão dialoga com Castellar (2017) na medida em que a autora considera a educação geográfica como um conhecimento que estrutura a leitura do mundo, na compreensão da formação espacial e desenvolvimento do pensamento espacial que promove a formação de cidadãos críticos. Corrobora também Callai (2018), na perspectiva de tratar a educação geográfica como instância que vincula o conhecimento geográfico com a formação cidadã, considerando a cidadania assentada no pertencimento ao lugar de vivência e ao sentido de comunidade. Assim, investir em um ensino que considere a escala de análise, para a interpretação do mundo da vida, é uma ferramenta intelectual no processo de entendimento do cotidiano, da identidade com o lugar e, consequentemente, visa uma aprendizagem implicada na formação para a cidadania.

Compreendemos que a educação cidadã está vinculada ao conhecimento e à vivência dos direitos e deveres de cada um, ao envolvimento dos sujeitos nas decisões e intervenções no mundo da vida e do trabalho. Nesse sentido, Freire (2000) nos diz que a capacidade de poder observar, comparar, avaliar, tomar decisões e intervir na vida da cidade é fundamental para o exercício da cidadania e, desse modo, é a expressão de uma presença no mundo não neutra.

Essa consciência, de saber qual é o papel de cada um na comunidade escolar, advém da capacidade que Freire (2000) nos fala. Contudo, é importante destacar que a mobilização para as ações e intervenções se dá pelo processo educativo, investigativo, o que, na maioria das vezes, ocorre no ambiente escolar, no transcurso de componentes curriculares da área de ciências humanas, em especial.

Brandão (2000), em constante interlocução com o pensamento de Paulo Freire e em um período do nosso país de intensas discussões sobre projetos educacionais emancipatórios e iniciativas de gestão democrática nas escolas, referia-se às práticas que produzem e sustentam a educação cidadã. Para o autor:

A educação cidadã [...] pretende fazer-se a si mesma uma construção solidária dos e entre os seus participantes [...]. Um trabalho pedagógico não apenas dirigido a uma comunidade aprendente preestabelecida canônica e estruturalmente, mas uma comunidade que, ao envolver-se com a sua educação [...] se recria a si mesma a cada momento (BRANDÃO, 2000, p.459-460).

É nesse contexto que a Geografia contribui para a formação crítica e cidadã, na busca por levantar e responder questões como: onde, por que e como determinadas coisas acontecem.

Relacionando a ideia de educação cidadã com a educação geográfica, consideramos pertinente a reflexão de Straforini (2018), que, ao fazer referência a um manifesto intitulado "Carta Aberta ao Parlamento Brasileiro: Porque Ensinar Geografia no Ensino Médio", anuncia que o papel da Geografia escolar é o de:

proporcionar aos alunos a formação na perspectiva do cidadão, que busque sempre a justiça e a equidade social a partir do processo de reflexão crítica sobre os fenômenos e eventos espaciais em suas múltiplas e indissociáveis escalas de análise (STRAFORINI, 2018, p.178).

Dessa forma, estabelece um campo de especificidade para a educação geográfica no processo de escolarização para o qual intencionamos contribuir. No caso das situações escolares, chamamos a atenção para a variedade de conteúdos apreendidos em sala de aula que possibilitam compreender o espaço construído, a ordenação territorial, a espacialidade e/ou territorialidade dos

$\begin{array}{lllll}\text { Caminhos de Geografia } & \text { Uberlândia-MG } & \text { v. 22, n. } 83 & \text { out./2021 } & \text { p. 276-286 Página } 277\end{array}$


fenômenos, bem como a escala de análise (CASTELLAR, 2006), possibilitando que a geografia escolar seja carregada de sentidos. Nessa disposição, excede a ideia de um ensino mais convencional, no qual as fronteiras disciplinares são bem demarcadas e os conteúdos são vinculados a uma tradição de definição curricular que se estabelece sem articulações com as vivências e experiências dos alunos.

Inclui-se na presente abordagem a importância da cartografia, que no campo das linguagens, contribui para o processo de ensino-aprendizagem (RICHTER, 2017). Assim, o professor juntamente com seus alunos pode explorar e trabalhar com a representação espacial, como forma de expressão e comunicação dos diversos saberes e conhecimentos produzidos.

Nesse sentido, compreendemos que a escola passa a ser entendida como um ambiente propício para a análise de fenômenos que envolvem a interação social. Desse modo, lançamos mão dos mapas mentais como estratégia pedagógica e investigativa para compreender as percepções dos estudantes sobre a escola e seu entorno, suas vivências, desejos e necessidades no espaço vivido.

As escolas e o seu complexo contexto de relações que se estabelecem entre alunos, professores, pais e direção, entre outros sujeitos, compõem as estruturas sociais e são, invariavelmente, permeadas de assimetrias, desigualdades, encontros e desencontros. Para compreendermos esse contexto, sustentamos que as categorias espaciais de análise, especialmente lugar e território, podem contribuir no estudo de como esse campo de forças se constitui e se caracteriza.

Moreira (2017), contribui nesse contexto dizendo que:

São as práticas e os saberes espaciais em sua reciprocidade interativa que comandam as relações de determinação entre a sociedade e o espaço em cada contexto de história. Assim, a escola como estrutura física, reflete as práticas espaciais, sempre em movimento, inferidas pelos sujeitos que ali interagem (MOREIRA, 2017, p. 17)

A interface do espaço social da escola com as diferentes dimensões das relações sociais, das quais emergem os conceitos de lugar e território, possibilita conduzir as pesquisas sob diversos aspectos. No que diz respeito ao conceito de lugar, Cavalcanti (2019), destaca que, pensar o lugar é antes de tudo, admitir a validade de que há um elo emotivo entre o homem e o ambiente em que ele vive. Sobre território, Souza (2016) traz a proposição de campos de força forjados nas relações sociais espacializadas, tendo sua existência vinculada à duração e manutenção dessas relações. Essa compreensão está implicada na dimensão política do território, a qual também se vincula aos aspectos culturais e simbólicos tendo em vista que, lugares são, menos ou mais claramente, e menos ou mais fortemente, quase sempre territórios (SOUZA, 2016).

Nesse sentido, inspirados em Lefebvre (2008), buscamos construir o aporte teórico das nossas pesquisas, as quais envolvem a escola, na sua dimensão física, os alunos e a comunidade na condição/dimensão social. Logo, as concepções do percebido (práticas espaciais); concebido (representações do espaço) e vivido (espaço representacional), fazem parte das discussões nesse contexto, pois conforme esclarece Schimid (2012), essa tríade é individual e social; é constitutiva da autoprodução do homem e da autoprodução da sociedade.

E quando Lefebvre (2008), fala sobre o espaço percebido ele quer dizer que é aquele da percepção comum à escala do indivíduo e de seu grupo, a família, a vizinhança. Já o concebido, trata-se, conforme Alves (2019), do espaço planejado, instituído, ou seja, um espaço que normatiza o que os cidadãos podem ou não fazer. Com relação ao espaço vivido, este é entendido na manifestação de Schmid (2012) como a experiência vivida do espaço. Essa dimensão significa o mundo assim como ele é experimentado pelos seres humanos na prática de sua vida cotidiana.

Diante disso, ponderamos que os desdobramentos em torno do objeto de pesquisa, ou seja, a escola como foco de estudo e os alunos como sujeitos, são pensados considerando a compreensão do espaço social como produto social dissimulado e inscrito no espaço e o entendimento de que toda a sociedade tem uma prática espacial e de que as relações sociais são relações socioespaciais as quais, conforme Lefebvre (2008), se conectam nas três dimensões da produção do espaço.

Como já mencionado anteriormente, a cartografia contribui de forma significativa como linguagem, a qual é manifestada a partir dos mapas mentais, como forma de comunicação. Estes por sua vez, tornam concretos os espaços representacionais (vivido) que Lefebvre (2008) traz em sua abordagem.

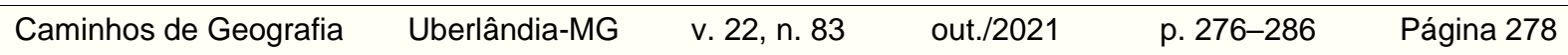


Nessa mesma perspectiva, destacamos as contribuições de Seemann (2006) em relação aos mapas mentais, o qual aponta que estes se tornam visões do mundo, espelhos da vida vivida, meios de comunicação e indicadores de emoções, medo e ideias, tornando-se uma forma de conhecimento visual.

A esse propósito, Archela; Gratão; Trostdorf (2004), destacam que:

os mapas mentais são imagens espaciais que as pessoas têm de lugares conhecidos, direta ou indiretamente. As representações espaciais mentais podem ser do espaço vivido no cotidiano, como por exemplo, os lugares construídos do presente ou do passado; de localidades espaciais distantes, ou ainda, formadas a partir de acontecimentos sociais, culturais, históricos e econômicos, divulgados nos meios de comunicação (ARCHELA; GRATÃO; TROSTDORF, 2004, p. 127)

A partir desses apontamentos, reforçamos a importância da utilização dos mapas mentais como recurso pedagógico potente e que pode ser explorado pelos professores em sala de aula, estimulando a criticidade e aguçando novos olhares dos diferentes sujeitos sobre as práticas e as relações espaciais. Os elementos representados e comunicados a partir dos mapas mentais serão explorados na seção a seguir.

\section{RELAÇÕES ESPACIAIS E PRÁTICAS ESPACIAIS POR MEIO DE MAPAS MENTAIS}

A pesquisa da qual tratamos parte da premissa de que há um distanciamento entre a escola e as comunidades de pertencimento dos estudantes. Ao fazermos esta afirmação nos reportamos às falas de professores da educação básica com os quais temos contato através de estágios, projetos de extensão e ações de formação continuada. Conforme os professores, esse distanciamento prejudica processos de ensino e aprendizagem, bem como os planejamentos pedagógicos. Porém, parece-nos que há pouca compreensão sobre o que caracteriza o distanciamento, bem como o que consideram como comunidade escolar.

Em relação aos professores da escola investigada, uma amostra indica que o tipo de vínculo com a comunidade escolar está pautado no fato de ela ter um pequeno número de alunos, de morarem no entorno da escola e de pessoas da mesma família frequentarem a instituição, favorecendo a constituição de um sentimento de grupo e de pertencimento. Ainda, a escola conta com uma experiência de mais de uma década de gestões eleitas que se pautam por uma prática democrática manifestada em reuniões pedagógicas e tomadas de decisões coletivas, organização de eventos e encontros abertos para a comunidade e uma orientação para a escuta dos estudantes na perspectiva de incluir algumas de suas demandas nas dinâmicas escolares e de acolher suas preferências na organização do espaço físico escolar.

Ao tratarmos destas características da escola, é importante explicitar que a escolha por ela se deu justamente por já ser uma escola com preocupações e ações voltadas para a comunidade escolar e, mesmo assim, reconhecer dificuldades em identificar expectativas, atributos e peculiaridades dos grupos de pertencimento dos estudantes. E ter no seu horizonte a ampliação do vínculo com a comunidade.

Em termos de localização geográfica, a escola encontra-se situada na porção Sul do estado do Rio Grande do Sul, no município de Capão do Leão, fazendo divisa com os municípios de Pelotas, Morro Redondo, Cerrito, Pedro Osório e Arroio Grande. Conta com uma população de 24.298 habitantes (IBGE, 2010).

Com relação aos aspectos econômicos, destacam-se as atividades de produção de arroz, soja, milho, melancia, sorgo, batatas, feijão, e fumo, como as principais. Também merece menção, as atividades de pecuária e silvicultura, com o cultivo e a extração de madeira como o eucalipto e acácia.

No que diz respeito aos aspectos educacionais, o município conta com um total de 3.766 alunos matriculados no ensino fundamental e 572 alunos matriculados no ensino médio. A taxa de escolarização de 6 a 14 anos de idade, fica em 95,3\%. Quanto à taxa de desempenho registrado em 2018, para o ensino fundamental, tem-se $79,90 \%$ de aprovação, $19,80 \%$ de reprovação e, $0,30 \%$ de evasão escolar (SEBRAE, 2019).

Em se tratando da escola investigada conta com um total de 162 alunos, distribuídos entre anos iniciais e anos finais do ensino fundamental. O sustento das famílias se dá através do trabalho, muitas vezes temporário, em agroindústrias vinculadas à produção e beneficiamento de arroz, conservas e

$\begin{array}{llllll}\text { Caminhos de Geografia } & \text { Uberlândia-MG } & \text { v. 22, n. 83 } & \text { out./2021 } & \text { p. 276-286 } & \text { Página } 279\end{array}$


laticínios, na produção familiar de doces, com serviços domésticos e no setor de transporte e serviços. A figura 1 mostra a localização da escola e das residências dos alunos no recorte temporal do ano letivo de 2018.

Figura 1 - Mapa de localização da escola e residências dos alunos no ano letivo de 2018.

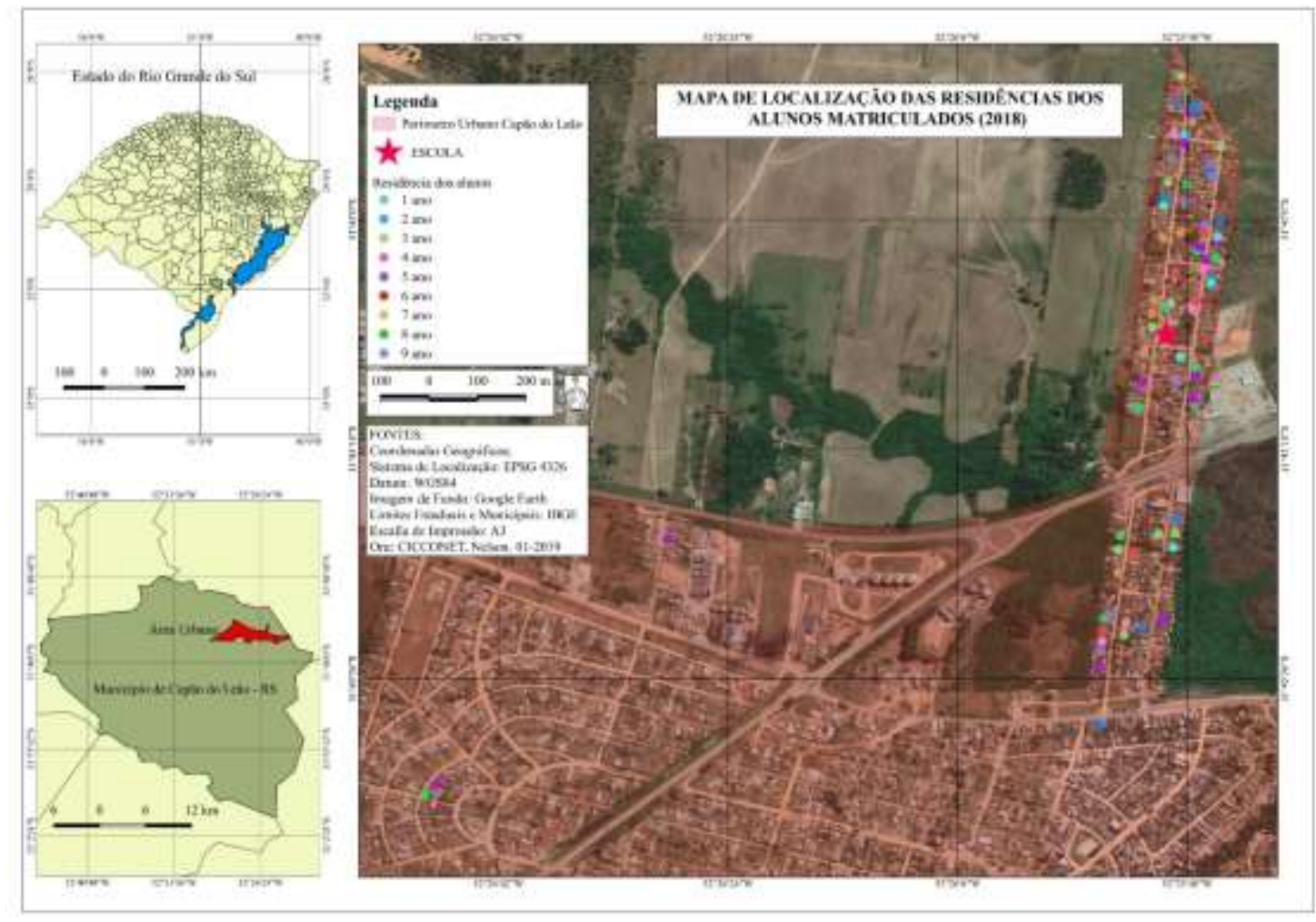

Fonte - Acervo de pesquisa. Organização: Cicconet (2019).

A figura 1 revela a proximidade do local de moradia e da escola bem como uma relação de vizinhança entre os alunos. As residências se distribuem em duas ruas paralelas que abrangem uma extensão média de 1,5 quilômetro cortados pela rodovia BR 116, dispondo os alunos em bairros distintos e com características similares, estando a escola em uma posição mediana.

Tendo em consideração essas características, foram sujeitos da investigação os estudantes da turma do nono ano da escola. A escolha da turma levou em consideração uma orientação por parte da direção, pois, apesar de já estarem na fase final de sua formação naquela instituição de ensino, são adolescentes e com desejos e expectativas que os professores têm dificuldade de apreender. Desse modo, se estabeleceu um primeiro compromisso da pesquisa com a gestão da escola, ou seja, colaborar na aproximação com as vivências daqueles estudantes. A adesão à turma indicada pela direção para serem sujeitos da pesquisa também se justificou pela faixa etária dos estudantes, que permite o deslocamento de forma independente até a escola, no qual podem realizar trajetos e observações próprias.

A produção de mapas mentais visou apreender representações espaciais e percepções da escola e dos demais lugares que integram o cotidiano dos estudantes. Cabe salientar que o processo de escolha dos mapas mentais, como estratégia de coleta de dados para essa série, considerou o domínio dos conceitos espaciais básicos da Geografia, como lugar e território, os quais contribuem para a construção do pensamento espacial.

Entendemos que a manifestação expressa pelos alunos nos mapas mentais é, na sua grande maioria, o reflexo das relações e intencionalidades que estes estabelecem com os espaços de vivências, é o próprio mundo em movimento, seja ele próximo ou distante. Ou seja, os mapas mentais são representações que revelam os valores do espaço vivido (CASTELLAR, 2012).

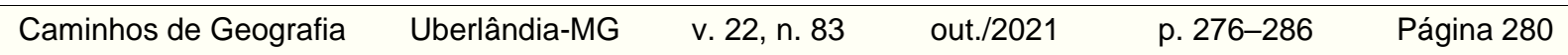


Nessa perspectiva, Kozel (2007) contribui de forma significativa quando diz que:

As representações provenientes das imagens mentais não existem dissociadas do processo de leitura que se faz do mundo. E nesse aspecto os mapas mentais são considerados uma representação do mundo real visto através do olhar particular de um ser humano, passando pelo aporte cognitivo, pela visão de mundo e intencionalidades. Essa multiplicidade de sentidos que um mesmo "lugar" contém para seus moradores e visitantes está ligada, sobretudo ao que se denomina de imaginação criadora, função cognitiva que ressalta a fabulação como vetor a partir do qual todo ser humano conhece o mundo que habita (KOZEL, 2007, p. 121).

Essa leitura de mundo particular, porém múltipla, realizada pelos alunos da escola, contribui de forma significativa para entendermos a organização espacial do espaço escolar e seu entorno, bem como, as relações socioespaciais dos sujeitos escolares e suas comunidades.

Como já destacamos, a intervenção foi realizada com uma turma do nono ano da escola, totalizando 27 alunos. As idades desses alunos variavam de 13 a 16 anos. Considerando que a escola se situa em um espaço periférico da cidade do Capão do Leão, todos os alunos que participaram da intervenção e que frequentam a escola, residem no seu entorno, o que permite o deslocamento casaescola-casa, da grande maioria, a pé. Essa condição se apresenta de forma positiva, pois, permite que esses alunos observem, analisem, interajam com amigos e vizinhos, exercitem o olhar crítico sobre o espaço.

Para conduzir metodologicamente a leitura e interpretação dos mapas mentais, nos inspiramos na metodologia de Kozel (2007), considerando como critérios de análise: interpretação quanto à forma de representação dos elementos na imagem; quanto à distribuição dos elementos na imagem; quanto à especificidade dos ícones: representação dos elementos da paisagem natural; representação dos elementos da paisagem construída; representação dos elementos móveis; representação dos elementos humanos; apresentação de outros aspectos ou particularidades. Também utilizamos como referência os elementos da imagem da cidade apontados por Lynch (1997) que são: caminhos (vias), limites, bairros, pontos nodais (nós) e marcos.

Após elaborados, os mapas mentais foram numerados para posterior análise, mantendo assim a privacidade dos informantes. Mesmo sendo representações individuais, percebemos que algumas se sobrepuseram e, nesse sentido, discutiremos alguns dos exemplares, os quais consideramos mais significativos para esta abordagem, analisando elementos que fazem parte do cotidiano dos alunos.

Conforme a análise realizada, alguns aspectos gerais foram percebidos nos mapas elaborados, como o deslocamento realizado pela maioria a pé, a localização de residências de colegas que são mais próximos, os quais possuem mais apreço, a falta de equipamentos urbanos, como saneamento básico e segurança, entre outros.

Nas representações, foi possível perceber aspectos de singularidade da comunidade, como a presença de animais soltos na rua, a exemplo de eqüinos e outros mais comuns, como cães. O distanciamento das áreas centrais das cidades proporciona essa característica peculiar, de um ritmo mais tranquilo, de ambiente pacato, com aspecto interiorano, em que as práticas espaciais são vivenciadas de forma coletiva, com maior interação entre os sujeitos. Por outro lado, tivemos registros nos mapas de jovens que necessitam estar conectados ao mundo, como em uma representação em que o aluno captura sinal de rede de wifi de um estabelecimento comercial.

Nesse contexto, Pereira e Seemann (2014), contribuem dizendo que:

Os desenhos evidenciam a Geografia presente naquele espaço, mostram claramente como as crianças percebem o seu espaço vivido, seja por narrativas dos mais velhos, seja por atividades diárias que realizam ou manifestações culturais das quais estão participando (PEREIRA e SEEMANN, 2014, p.55).

A expressão de alguns termos como "vendinha" é algo peculiar, característica de empreendimentos de bairro, o que não é comum ser percebido em centros urbanos maiores. Outro elemento que nos chamou a atenção foi o uso do termo "Pedra antiga", o qual refere-se, de fato, a uma grande pedra existente num entroncamento, próximo da escola, ponto de referência da localidade. Nomes como "Venda Anarulina", "Toca do Coelho" e "Piro" são destaques em boa parte dos mapas, que buscam representar estabelecimentos comerciais frequentados por eles e/ou familiares. Também foi recorrente a palavra "Pingo", indicando a sede de um clube de futebol local.

$\begin{array}{lllll}\text { Caminhos de Geografia } & \text { Uberlândia-MG } & \text { v. 22, n. } 83 & \text { out./2021 } & \text { p. 276-286 }\end{array}$ Página 281


Algumas das representações trouxeram de forma clara a manifestação de problemas sociais presentes nas cidades ou bairros periféricos, o uso/comercialização de entorpecentes. Muitas vezes o entorno das escolas é local de atração para possíveis consumidores, o que requer um trabalho intenso de conscientização, por parte da escola e dos familiares, sobre os reflexos negativos que esta situação pode acarretar.

Com base no que foi exposto, e com relação à leitura metodológica de Kozel (2007) e Lynch (1991), podemos perceber, a título de exemplos, que as figuras 2 (aluno 1), 3 (aluno 9) e 4 (aluno 27), trazem elementos construídos da paisagem e elementos móveis como destaque. Outros elementos da imagem, como letras e palavras também foram percebidos. Alguns marcos e o caminho estão bem delineados pelos alunos, trazendo de forma bem expressiva a presença de buracos nos trajetos. Interessante mencionar que alguns elementos da cartografia se fazem presentes nestas representações, como o uso de cores, título e legenda.

Figura 2 - Representação do trajeto casa-escola-casa (aluno 1), do nono ano.

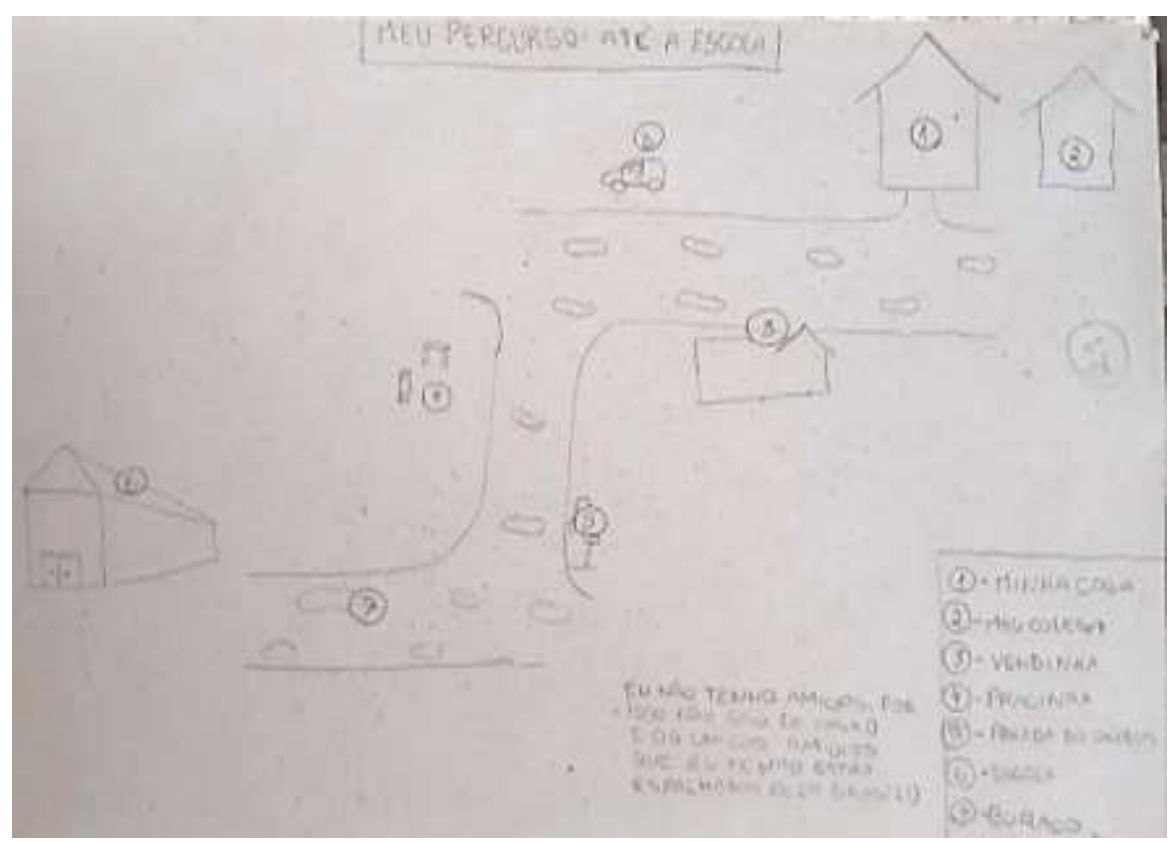

Fonte - Autoras (2019).

Esta representação nos chama a atenção em alguns aspectos já mencionados, em que o aluno aponta a existência/ausência de equipamentos urbanos, tão importantes para a dinâmica da comunidade local, como ponto de ônibus, pracinha, vendinha e os buracos, os quais mostram a necessidade de adequações para possibilitar melhor mobilidade e interação das pessoas. $\mathrm{Na}$ representação é possível perceber a manifestação de que não possui um círculo de amigos que pudesse ser significativo, o que nos leva a crer que não convive e nem circula cotidianamente pelo bairro, diferentemente de outras representações com o registro de residências de colegas mais próximos, nominadas como "casa da minha melhor amiga", "casa da minha crush", "casa da minha dinda".

$\mathrm{Na}$ figura 3, tem-se a representação dos elementos da paisagem de forma horizontal, trazendo detalhes simétricos nos desenhos, destacando a presença de animais soltos no bairro, mercado, igreja, ponto de ônibus e a quadra da escola. Noutras representações, como aspectos associados, foi possível perceber a manifestação em forma de escrita, que o bairro necessita de canil para cuidar de animais, de calçadas para melhor mobilidade das pessoas e de sorveteria para momentos de interação.

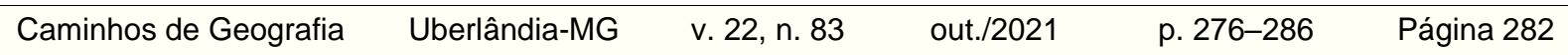


Figura 3 - Representação do trajeto casa-escola-casa (aluno 9) do nono ano.

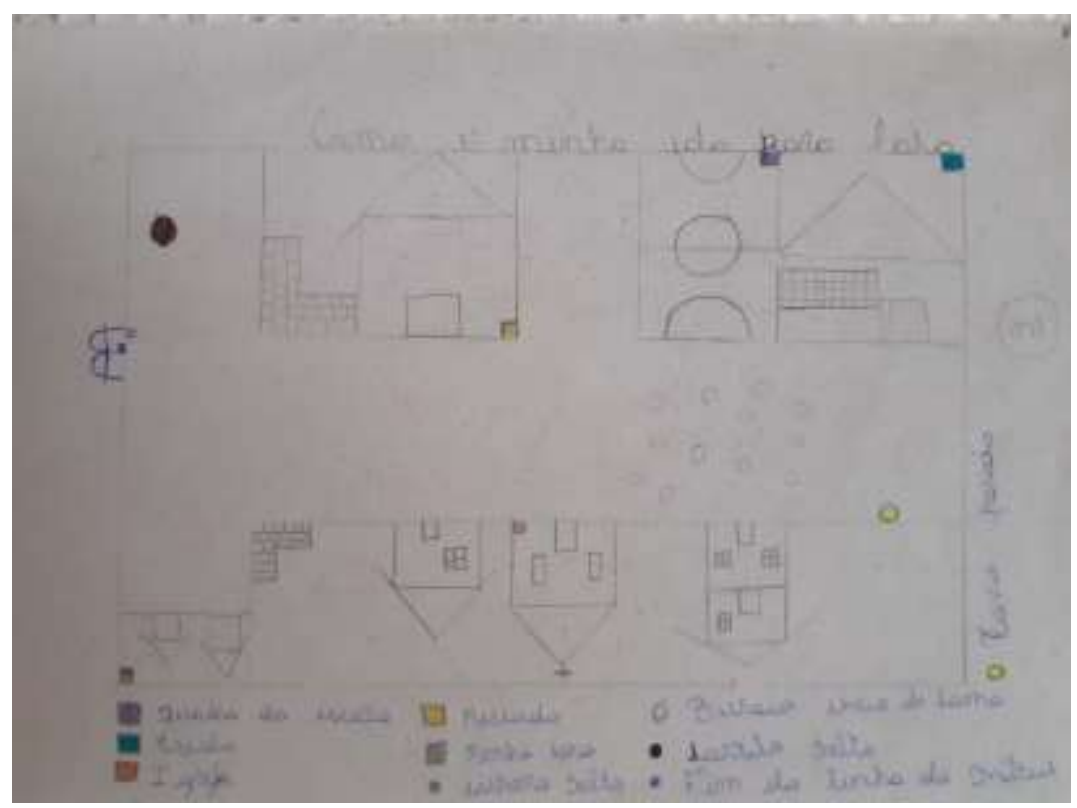

Fonte - Autoras (2019)

A figura 4 traz, conforme Kozel (2007), informações sobre a interpretação quanto à forma de representação dos elementos na imagem, letras e palavras complementando a representação. $\mathrm{Na}$ representação é possível observar a manifestação em forma de texto em que o aluno 27 escreve "eu gosto de morar perto da escola" e que "a quadra é boa para muitas coisas". A segunda manifestação é em relação à quadra da escola, pois é um dos únicos espaços de lazer no bairro, utilizados pelos alunos e pela comunidade, principalmente nos finais de semana, para recreação e esportes. É um espaço aberto, sem muros ou grades o que permite o acesso das pessoas para diferentes práticas. Esses aspectos revelam o vínculo afetivo com o espaço que é público e que faz parte da vida cotidiana não só dos alunos, mas da comunidade como um todo.

Figura 4 - Representação do trajeto casa-escola-casa (aluno 27) do nono ano.

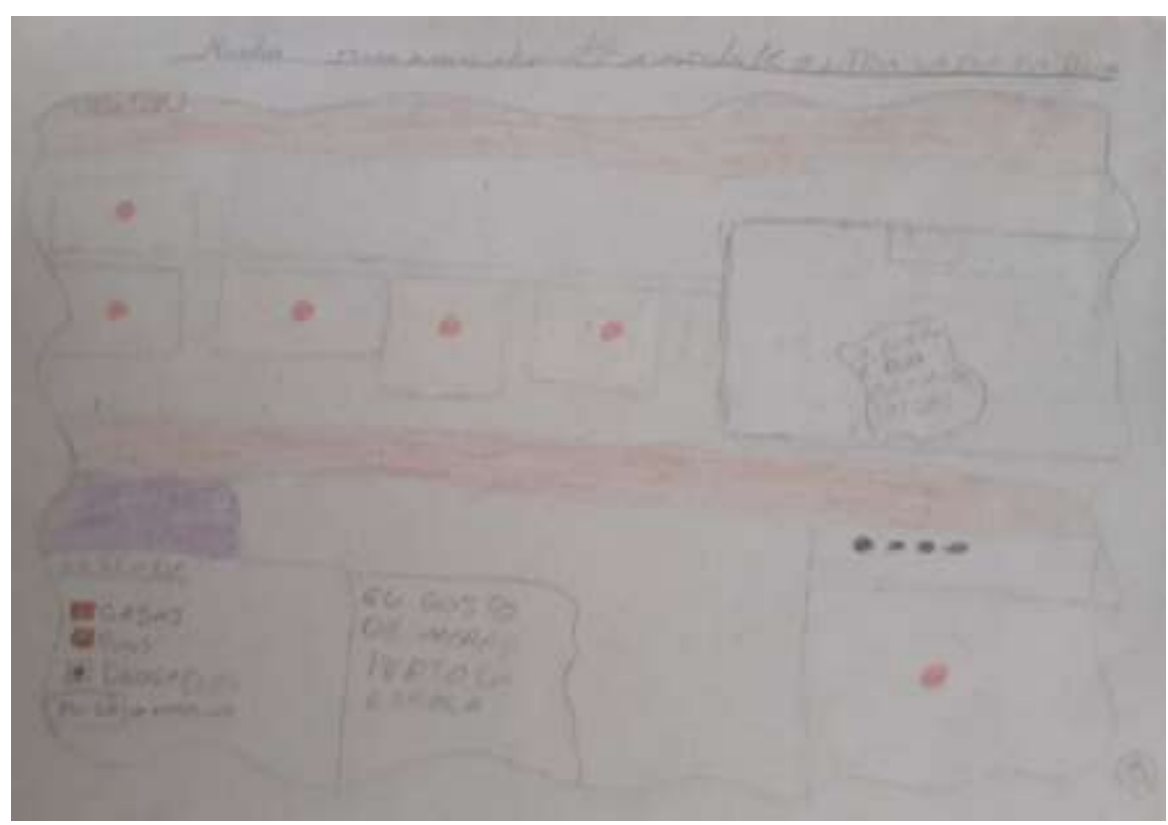

Fonte - Autoras (2019).

$\begin{array}{lllll}\text { Caminhos de Geografia } & \text { Uberlândia-MG } & \text { v. 22, n. } 83 & \text { out./2021 } & \text { p. 276-286 Página } 283\end{array}$


Outro elemento que nos chama a atenção nessa representação é a presença, novamente, de simbologia para a presença de usuários de drogas no entorno da escola.

No processo de realização dos mapas mentais, solicitamos aos estudantes que escrevessem sobre o que consideravam dever ser melhorado ou acrescido para que a comunidade se tornasse um lugar mais adequado para viverem. Dos 27 participantes, 20 atenderam a solicitação. Nas escritas encontramos a indicação de ausências naquele espaço urbano. São elas: pista de skate, praça arrumada, quadra esportiva coberta, escola de música, banco na calçada da escola, ponto coleta seletiva de lixo, sorveteria, escola de ensino médio, rua asfaltada, farmácia, padaria, posto de saúde, parque, centro cultural, internet na escola, coleta de lixo mais frequente, esgotos fechados, creche, pronto socorro, delegacia, academia de ginástica, restaurante, lan house e iluminação pública. Ao verificarmos a frequência dessas indicações, identificamos que todas foram citadas por mais de um estudante, porém, a sorveteria foi indicada por dez deles, seguida da quadra esportiva coberta indicada por nove estudantes. A necessidade de asfalto nas ruas foi citada por cinco, farmácia e posto de saúde por quatro estudantes.

Os jovens mostraram preocupação com a vida coletiva e cotidiana da comunidade ao pensarem no posto de saúde, na farmácia, no saneamento, na coleta e destinação do lixo. Porém, a sorveteria e a quadra esportiva coberta assinalam a necessidade de locais de encontro e atividades de lazer, tão significativas na juventude.

Outro aspecto que consideramos interessante com relação aos registros dos alunos, foi de que não houve manifestação quanto ao desejo de mudar de bairro, morar noutro lugar, ou de que não gostam de morar ali. Ao contrário, os dados demonstraram que o lugar onde moram e os espaços de interação são importantes para a dinâmica do cotidiano de cada um. Que esses espaços necessitam ser mais bem visibilizados e valorizados, para que a cidadania possa ser exercida de forma efetiva.

A partir do que foi exposto, consideramos importante salientar que diante de aspectos que envolvem relações socioespaciais e práticas espaciais, seja por meio das vivências e de problemáticas demandas da comunidade ou dos estudantes participantes desta pesquisa, o papel da escola, por meio dos gestores e professores, são fundamentais, pois são os canais de aproximação, comunicação e referência para compreenderem o espaço em que vivem. Frente a esta afirmação, Cavalcanti (2019), destaca que a Geografia no contexto da escola, possibilita ao aluno perceber relações entre seu posicionamento espacial e seu lugar na sociedade frente às problemáticas em que vive, buscando, assim, elementos para uma intervenção crítica no espaço.

Logo, acreditamos que as diferentes manifestações apontadas pelos alunos por meio dos mapas mentais, reforçam a riqueza de material que a escola poderá se apropriar e incluir na lista das discussões, nos planejamentos e projetos pedagógicos.

\section{CONSIDERAÇÕES SOBRE O PROCESSO}

Reconhecemos que as práticas pedagógicas da escola têm densidade social e espacial, considerando as dinâmicas da formação, os limites e possibilidades do espaço físico escolar, as expectativas curriculares, os investimentos pedagógicos realizados na perspectiva de uma escola mais democrática e as características socioculturais e econômicas da localidade.

O uso e o significado que as pessoas dão ao espaço, efetivamente, conferem a ele o atributo de público. Assim, interessou-nos compreender como o espaço da escola é vivenciado, as formas de sua ocupação e a relação entre a ausência e a presença de identidade com o lugar e com a cultura local nas percepções dos estudantes, bem como identificar a constituição dos tensionamentos nas relações sociais que produzem o território escolar. Consideramos que as aproximações e os distanciamentos entre a escola e a comunidade estão vinculados ao tipo de ocupação e vivência no espaço social daquela localidade.

$\begin{array}{llllll}\text { Caminhos de Geografia } & \text { Uberlândia-MG } & \text { v. 22, n. } 83 & \text { out./2021 } & \text { p. 276-286 } & \text { Página } 284\end{array}$


A análise dos dados trouxe indicadores sobre o conceito de lugar, entendido como uma dimensão cultural e simbólica que envolve as identidades e as espacialidades vividas e percebidas, nos seguintes aspectos:

a) Estudantes revelaram querer permanecer e qualificar a comunidade, inclusive anseiam por uma escola de ensino médio, o que permitiria continuar os estudos na localidade;

b) Não manifestaram críticas ao modo de funcionamento da escola, provavelmente resultado do trabalho pedagógico e de gestão escolar já existente. A escola é representada nos mapas mentais de modo cuidadoso e detalhado, o que entendemos sinalizar apreço e reconhecimento pela instituição;

c) Informam como é o cotidiano local através da indicação de ausências: falta de calçamento, de áreas de lazer públicas e de comércios de bens de consumo associados à saúde como farmácias e de lazer como uma sorveteria;

d) Manifestam desejos e problemas associados à juventude global como o convívio com situações de uso e comércio de drogas na proximidade da escola e a precariedade de acesso à internet.

No que se refere ao território, campo de forças constituído pelas relações sociais daquele grupo, os estudantes explicitaram práticas espaciais de territorialização na existência de um microterritório identificado como local de venda de drogas na proximidade da escola e o uso da quadra de esportes como local de encontro, socialização e manutenção de vínculos sociais. Além disso, o território também se constitui na falta e nos incômodos vivenciados pelos moradores e percebidos pelos estudantes. Os buracos nas ruas foram representados com regularidade, bem como a ausência de coleta de lixo sistemática, posto de saúde e farmácia.

Entendemos que o interesse pelo entorno escolar e pelos locais de moradia e vivência dos estudantes por parte dos docentes e da gestão escolar contribui na qualificação das dinâmicas escolares e na proposição de projetos político-pedagógicos implicados com a noção de cidadania anunciada no início do texto. O currículo escolar pode incorporar, do ponto de vista da educação geográfica e das demais áreas do conhecimento, a compreensão crítica do espaço social, com sensibilidade e compromisso diante das singularidades dos sentidos de lugar e dos territórios envolvidos com a escola.

Com os achados da pesquisa queremos anunciar que a escola investigada não é mais uma dentre tantas escolas periféricas em que muitas carências e vivências estão presentes, é uma escola singular como todas são e assim devem ser percebidas. As características socioespaciais, o sentido que aquela comunidade dá para o espaço vivido, como se constitui o espaço percebido por ela devem estar implicados na organização curricular e na definição do projeto político pedagógico.

Os mapas mentais são uma forma de acesso potente, apesar de não a única, para quem aposta em uma escola democrática e que exerce o tanto de autonomia que lhe cabe. Quando os estudantes manifestam querer permanecer na comunidade identificamos ser o resultado de um processo de naturalização da falta e da precariedade, mas, também, o efeito de uma identidade com o lugar. Essas questões podem ser problematizadas no currículo escolar, servirem de eixos de estudo nas diferentes disciplinas, serem tematizadas e destrinchadas a partir de diferentes áreas do conhecimento. Uma utopia diante das tantas dificuldades do exercício da profissão? Sim, mas, quem somos nós se não apostarmos nas utopias?

\section{REFERÊNCIAS}

ALVES, G. A. A produção do espaço a partir da tríade lefebvriana concebido/percebido/vivido.

Geousp - Espaço e Tempo (Online), v. 23, n. 3, p. 551-563, 2019.

https://doi.org/10.11606/issn.2179-0892.geousp.2019.163307

ARCHELA, R. S.; GRATÃO, L. H. B.; TROSTDORF, M. A. S. O lugar dos mapas mentais na representação do lugar. GEOGRAFIA (LONDRINA), v. 13, n. 1, p.127-141, 2004. Disponível em http://www.geo.uel.br/revista. Acesso em: 15 de maio de 2020.

CALLAI, H.C. Educação Geográfica para a formação cidadã. Revista de Geografia Norte Grande, 70: p. 9-30, 2018. https://doi.org/10.4067/S0718-34022018000200009

$\begin{array}{lllll}\text { Caminhos de Geografia } & \text { Uberlândia-MG } & \text { v. 22, n. } 83 & \text { out./2021 } & \text { p. 276-286 }\end{array}$


CASTELLAR, S. M. V. Currículo, educação geográfica e formação docente: desafios e perspectivas. Revista Tamoios, Ano 2, n. 2, p. 1-14, 2006.

CASTELLAR, S. M. V. Ensino de geografia. 2.ed. São Paulo: Cengage Learning, 2012.

CASTELLAR, S. M. V.; JULIASZ, P.C. S. Educação geográfica e pensamento espacial: conceitos e representações. ACTA Geográfica, Boa Vista, Edição Especial, p.160-178. 2017.

FREIRE, P. Pedagogia da indignação. São Paulo: UNESP, 2000.

KOZEL, S. Mapas mentais - uma forma de linguagem: perspectivas metodológicas. In: KOZEL, S. [et al] (orgs.). Da percepção e cognição a representação: reconstrução teóricas da Geografia Cultural e Humanista. São Paulo: Terceira Margem; Curitiba: NEER, 2007. p. 114-138.

LEFEBVRE, H. A produção do espaço. Trad. Doralice Barros Pereira e Sérgio Martins (do original: La produción de l' espace. 4 éd. Paris: É. Anthropos, 2000). Primeira versão, 2006. Disponível em: https://gpect.files.wordpress.com/2014/06/henri lefebvre-a-produc3a7c3a3o-do-espac3a7o.pdf Acesso em: abril de 2018.

LEFEBVRE, H. Espaço e Política. Belo Horizonte: Ed. da UFMG, 2008.

LYNCH, K. A imagem da cidade. São Paulo: Martins Fontes, 1997.

LOPES, J. R. A escola como espaço social, prática pedagógica e processo de trabalho: reflexões. Campinas: Pro-Posições. Unicamp, v.1 n.5 (32), p. 61-68, 2000.

MOREIRA, R. Uma ciência das práticas e saberes espaciais. Rev. Tamoios, São Gonçalo (RJ), ano 13, n. 2, págs. 26-43, 2017. https://doi.org/10.12957/tamoios.2017.30458

PEREIRA, C. E. G; SEEMANN, J. (Re) apresentações cartográficas do espaço municipal mapas artísticos em deriva da cartografia escolar. Revista Geografares, Edição Especial, p.48-65, 2014.

RICHTER, Denis. A linguagem cartográfica no ensino de Geografia. Revista Brasileira de Educação em Geografia, Campinas, v. 7, n. 13, p. 277-300, jan./jun., 2017. https://doi.org/10.46789/edugeo.v7i13.511

SCHMID, Christian. A teoria da produção do espaço de Henri Lefebvre: em direção a uma dialética tridimencional. In: GEOUSP - espaço e tempo. São Paulo: N`32, p. 89- 109, 2012. https://doi.org/10.11606/issn.2179-0892.geousp.2012.74284

SEBRAE - Serviço de Apoio às Micro e Pequenas Empresas do Rio Grande do Sul. Perfil das cidades Gaúchas 2019 - Capão do Leão.

$<$ https://datasebrae.com.br/municipios/rs/Perfil Cidades Gauchas-Capao do Leao.pdf >. Acesso em: 23 de julho de 2020.

SEEMANN, J. Interpretação de mapas infantis em escala mundial: reflexões sobre a percepção, representação e a geografia das crianças. OLAN. Ciência e Tecnologia, vol.6, n. 1, p. 107-120, 2006.

SOUZA, M. L. Os conceitos fundamentais da pesquisa sócio-espacial. Rio de Janeiro: Bertrand Brasil, 2016.

STRAFORINI, R. O ensino de Geografia como prática espacial de significação. Revista Estudos Avançados, vol.32 n.93, p.175-195, 2018.

Recebido em: 04/08/2020

Aceito para publicação em: 18/03/2021 